\title{
Successful peroral endoscopic removal of migrated metal stent
}

Duodenal covered self-expandable metal stents (C-SEMSs) are designed with stent mesh to prevent tumor ingrowth [1]. However, stent migration is a major adverse event associated with C-SEMS, occurring in $8 \%-25 \%$ of cases [2,3]. In some cases, migrated stents exit via the rectum or remain in the body without complications [4]. However, when stent migration causes an intestinal obstruction, surgical removal is required [5]. To our knowledge, there are few reports of migrated SEMS removal via peroral endoscopy. Here, we outline a case of successful removal of a migrated duodenal C-SEMS using enteroscopy through an expanded second duodenal SEMS ( Video 1).

An 80-year-old man diagnosed with a malignant duodenal obstruction caused by pancreatic cancer underwent endoscopic duodenal C-SEMS placement ( $\triangleright$ Fig.1). He was discharged once he was able to consume food by mouth. He was admitted to the emergency ward 17 days after the procedure with abdominal distension and vomiting.

Computed tomography showed that the stent had migrated into the jejunum, causing an intestinal obstruction without perforation ( $\boldsymbol{\nabla}$ Fig. 2 ). As the position of the migrated stent did not change on follow-up X-rays, we decided to remove the stent using enteroscopy. However, the enteroscope would not pass because of duodenal stenosis, so we decided to place a second duodenal SEMS ( $\vee$ Fig. 3). The second SEMS was fully expanded 2 days later, and we successfully passed the stenosis and reached the first, migrated C-SEMS. To prevent gastrointestinal injury during stent removal, we attached an overtube to the enteroscope and gently placed it through the stenosis. Using grasping forceps and a snare, we captured the migrated C-SEMS within the overtube and safely removed it per

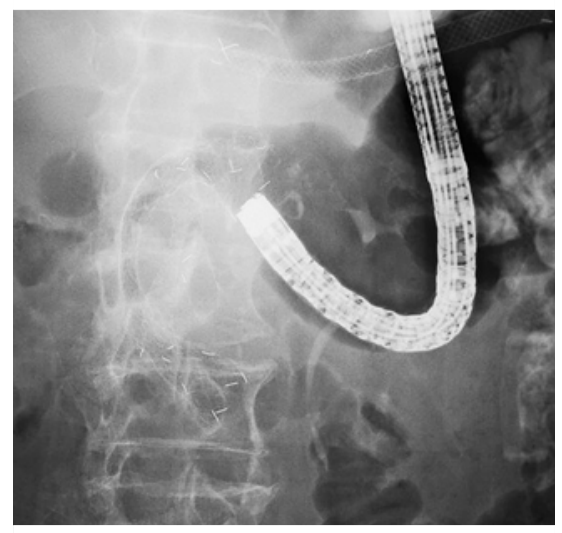

- Fig. 1 A covered self-expandable metal stent was successfully placed for duodenal obstruction caused by pancreatic cancer.

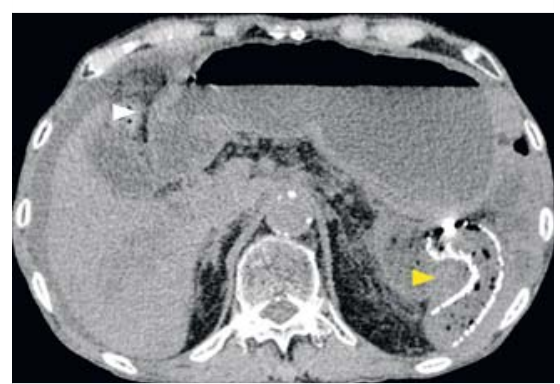

- Fig. 2 The stent migrated into the jejunum (yellow triangle), and we confirmed intestinal obstruction (white triangle) without perforation.

orally ( $>$ Fig.4). No necrosis or perforation was observed where the migrated C-SEMS had been stuck. After SEMS removal, the patients' symptoms resolved. This technique might be a useful option for removing a migrated SEMS per orally without surgery.

Endoscopy_UCTN_Code_CPL_1AH_2AD

\section{Competing interests}

None

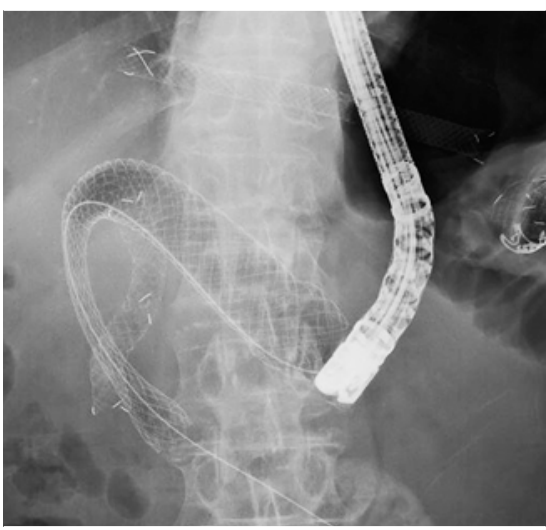

- Fig. 3 The enteroscope could not pass the malignant duodenal stenosis; therefore, we placed a second duodenal selfexpandable metal stent. Even with balloon dilation, we were unable to pass through the duodenal stenosis.

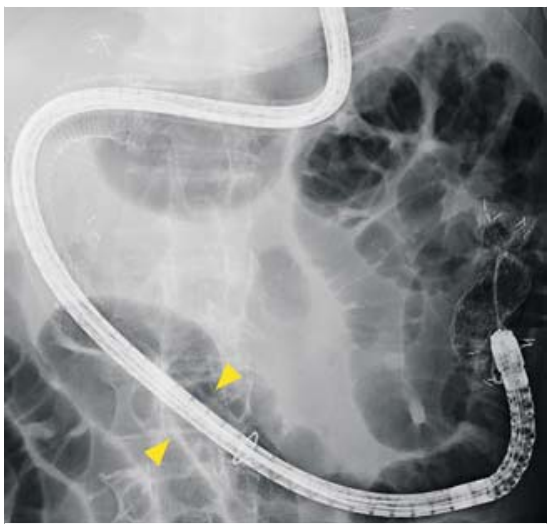

Fig. 4 The second self-expandable metal stent (SEMS) was fully expanded 2 days after duodenal placement, and we were able to pass through the duodenal stenosis. We were then able to reach the first migrated covered SEMS that had lodged in the jejunum. Next, we placed the overtube through the duodenal stenosis (yellow triangle) and straightened the proximal enteroscope. Using grasping forceps and a snare, we successfully captured the migrated covered SEMS within the overtube and safely removed it per orally. 


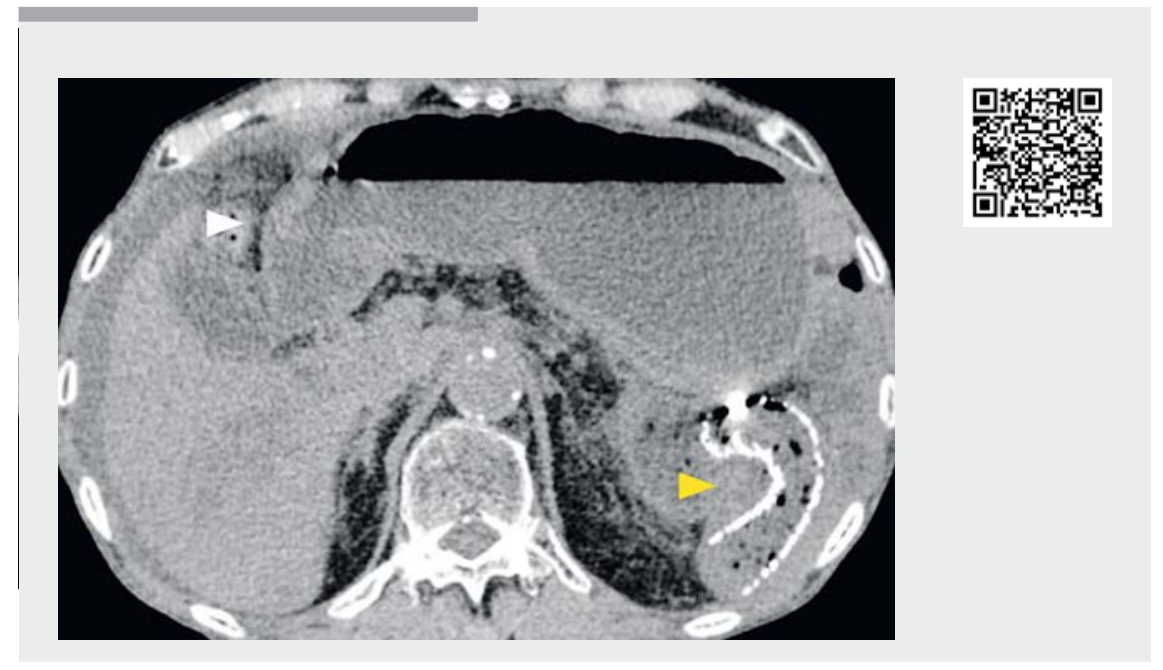

Video 1 Successful peroral removal of a migrated self-expandable metal stent using an enteroscope. (Yellow triangle, stent; white triangle, obstruction.)

\section{The authors}

Yasuki Hori ${ }^{1}$, Kazuki Hayashi ${ }^{1}$, Yu Sobajima², Itaru Naitoh', Katsuyuki Miyabe', Michihiro Yoshida ${ }^{1}$, Hiromi Kataoka ${ }^{1}$

1 Department of Gastroenterology and Metabolism, Nagoya City University Graduate School of Medical Sciences, Nagoya, Japan

2 Department of Gastroenterology, Ichinomiya Municipal Hospital, Ichinomiya, Japan

\section{Corresponding author}

\section{Yasuki Hori, MD, PhD}

Department of Gastroenterology and Metabolism, Nagoya City University Graduate School of Medical Sciences, 1 Kawasumi, Mizuho-cho, Mizuho-ku Nagoya 467-8601, Japan

Fax: +81-52-8520952

yhori@med.nagoya-cu.ac.jp

\section{References}

[1] Hori Y, Naitoh I, Hayashi K et al. Predictors of outcomes in patients undergoing covered and uncovered self-expandable metal stent placement for malignant gastric outlet obstruction: a multicenter study. Gastrointest Endosc 2017; 85: 340 - 348.e1

[2] Hori Y, Naitoh I, Hayashi K et al. Predictors of stent dysfunction after self-expandable metal stent placement for malignant gastric outlet obstruction: tumor ingrowth in uncovered stents and migration of covered stents. Surg Endosc 2017; 31: 4165-4173

[3] Pan YM, Pan J, Guo LK et al. Covered versus uncovered self-expandable metallic stents for palliation of malignant gastric outlet obstruction: a systematic review and metaanalysis. BMC Gastroenterol 2014; 14: 170

[4] Hori Y, Naitoh I, Hayashi K et al. Covered duodenal self-expandable metal stents prolong biliary stent patency in double stenting: the largest series of bilioduodenal obstruction. J Gastroenterol Hepatol 2018; 33: $696-703$

[5] Ko HK, Song HY, Shin JH et al. Fate of migrated esophageal and gastroduodenal stents: experience in 70 patients. J Vasc Interv Radiol 2007; 18: 725-732

\section{Bibliography}

DOI https://doi.org/10.1055/a-0915-1756

Published online: 4.6.2019

Endoscopy 2019; 51: E339-E340

(c) Georg Thieme Verlag KG

Stuttgart · New York

ISSN 0013-726X

\section{ENDOSCOPY E-VIDEOS \\ https://eref.thieme.de/e-videos}

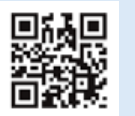

Endoscopy E-Videos is a free access online section, reporting on interesting cases and new

techniques in gastroenterological endoscopy. All papers include a high quality video and all contributions are freely accessible online.

This section has its own submission website at https://mc.manuscriptcentral.com/e-videos 